\title{
Sinopse dos Chryxinae (Hemiptera, Reduviidae)
}

\section{Hélcio R. Gil-Santana 1; Luiz A. A. Costa ${ }^{2} \&$ Oton M. Marques ${ }^{3}$}

\author{
${ }^{1}$ Laboratório de Diptera, Departamento de Entomologia, Instituto Oswaldo Cruz. Avenida Brasil 4365, Manguinhos, \\ 21045-900 Rio de Janeiro, Rio de Janeiro, Brasil. E-mail: helciogil@uol.com.br \\ 2 Museu Nacional, Universidade Federal do Rio de Janeiro. 20940-040 Quinta da Boa Vista, Rio de Janeiro, Rio de Janeiro, \\ Brasil. \\ ${ }^{3}$ Departamento de Fitotecnia, Centro de Ciências Agrárias e Ambientais, Universidade Federal da Bahia. 44380-000 Cruz \\ das Almas, Bahia, Brasil. E-mail: oton@ufba.br
}

\begin{abstract}
Synopsis of the Chryxinae (Hemiptera, Reduviidae). Synopsis of the Chryxinae with keys to the genera and species of the subfamily are presented. Chryxus bahianus sp. nov. and the male of Wygodzinskyella travassosi (Lent \& Wygodzinsky, 1944) are described.

KEY WORDS. Bahia; Heteroptera; Insecta; new taxa; taxonomy.
\end{abstract}

RESUMO. Uma sinopse da taxonomia dos Chryxinae com chaves para os gêneros e espécies da subfamília são apresentados. Chryxus bahianus sp. nov. e o macho de Wygodzinskyella travassosi (Lent \& Wygodzinsky, 1944) são descritos.

PALAVRAS-CHAVE. Bahia; Heteroptera; Insecta; novos taxa; taxonomia.

A subfamília Chryxinaefoi proposta por ChAM PION (1898). Atualmente é composta por três gêneros monotípicos: Chryxus Champion, 1898, Lentia Wygodzinsky, 1946 e W ygodzinskyella Usinger, 1952, com as espécies C. tomentosus Champion, 1898, L. corcovadensis Wygodzinsky, 1946 e W. travassosi (Lent \& Wygodzinsky, 1944) (WYgodzinsky 1949, Putshkov \& Putshioov 1985, Maldonado Capriles 1990, Schuh \& Slater 1995, Forero 2004). LENT \& WYGODZINSKY (1944) consideraram o táxon como "uma subfamília raríssima".

Chryxus tomentosus Champion, 1898 foi descrita com base em dois espécimes machos, sintipos, coletados no Panamá (Fig. 1) (ChAMpion 1898, UsInger 1952).

Chryxus travassosi foi descrita com base no holótipo fêmea, proveniente do Estado de Mato Grosso, Brasil (Lent \& WYGODZINSKY 1944).

Lentia corcovadensis (Fig. 2) foi descrita a partir do holótipo fêmea, coletado pelo próprio autor na floresta do Morro do Corcovado, cidade e Estado do Rio de Janeiro, Brasil (WYGodzInSkY 1946). Esse autor chamou a atenção para a semeIhança do inseto vivo, tanto pelos seus movimentos quanto pela coloração, com alguns Anthocoridae e Miridae, particuIarmente Fulvius quadristillatus Stål, 1860, os quais foram encontradosjuntos na natureza (WYGODZINSKY 1946, SCHUH \& SLATER 1995). Segundo WYGODZINSKY (1946), os caracteres que separam Lentia de Chryxus são os seguintes: cabeça muito larga; ocelos presentes; cabeça com um par de processos aguçados na face ventral (esboçados em Chryxus); colo muito curto; cório com as nervuras distintas e com pequena célula costal; forma geral mais estreita e delicada.

A presença ou ausência de ocelos nas formas aladas tem sido considerada de importância primordial na sistemática de Reduviidae (CHAM PION 1898), constituindo um caráter constante nas outras subfamílias (Usinger 1943, Schun \& SLATER 1995). Chryxinae é a primeira subfamília de Reduviidae que inclui gêneros e espécies com hemiélitros e asas normais com ou sem ocelos (WYGODZINSKY 1946).

Champion (1898) forneceu uma diagnose da subfamília, revista por WYGODZINSKY (1946), considerando o conhecimento obtido com a descoberta de novos membros de Chryxinae, incluindo a presença de ocelos em Lentia corcovadensis e sua ausência nas outras espécies.

Todos os autores mencionados forneceram descrições detal hadas e boas ilustrações dos táxons, incluindo a descrição das estruturas da genitália feminina de W. travassosi (LENT \& WYGODZINSKY 1944) e L. corcovadensis (WYGodZINSKY 1946), não apresentando nenhum estudo das estruturas genitais masculinas de Chryxinae até o momento.

USINGER (1952) relatou a existência de um terceiro espécime de $\mathrm{C}$. tomentosus coletado na Guiana, depositado em The Natural History Museum (BMNH), de um exemplar fêmea de W. travassosi coletado em Misiones, Argentina, e depositado no Museu de Paris (MNHN) e da informação de Wygodzinsky sobre a coleta de um macho desta última espécie no interior de uma casa no Estado de São Paulo, Brasil. 
USINGER (1952) erigiu W ygodzinskyella Usinger, 1952 para incluir C. travassosi. As diferenças apontadas entre Chryxus e W ygodzinskyella foram: 1) espinho escutelar engrossado no ápice em Chryxus e aplainado em W ygodzinskyella; 2) nervuras distintas na metade basal do cório em Chryxus, e praticamente indistintas em W ygodzinskyella; 3) conexivo de coloração alternada e pernas de coloração clara uniforme em Chryxus, conexivo de coloração uniforme com pernas com marcações escurecidas em W ygodzinskyella; 4) Chryxus com cerca de metade do comprimento de $W$ ygodzinskyella.

FORERO (2004) considerou a possibilidade deW ygodzinskyella ser sinônimo de Chryxus, tendo em vista que os caracteres que os separam são débeis e o material observado mostra gradação entre os mesmos. Esse mesmo autor, também considerou possível haver um certo grau de dimorfismo sexual, considerando necessária uma revisão da subfamília e que um estudo da genitália masculina poderia ajudar no esclarecimento das relações entre os gêneros de Chryxinae.

Neste trabalho, os autores apresentam a descrição de Chryxus bahianus sp. nov. (Figs 3-12) e o macho de W. travassosi (Figs 13-22), incluindo as características da genitália masculina de ambas espécies.

\section{MATERIAL E MÉTODOS}

O material-tipo de $\mathrm{C}$. tomentosus permanece depositado no The Natural History Museum (BMNH), Londres, Inglaterra (Fig. 1), conforme informações do Prof. Dr. Michael Webb, dessa Instituição.

O holótipo de L. corcovadensis, originalmente depositado no extinto Instituto de Ecologia e Experimentação Agrícola (I.E.E.A.), encontra-se atualmente na Coleção Entomológica do Museu Nacional da Universidade Federal do Rio de Janeiro (MNRJ), em perfeitas condições de preservação.

Além do holótipo de W. travassosi depositado na Coleção Entomológica "Herman Lent" do Instituto Oswaldo Cruz (IOC) (LENT \& WYGODZINSKY 1944), encontrou-se três exemplares machos dessa espécie, identificados por um dos autores da mesma, Prof. H. Lent, nas Coleções do IOC e do Museu Nacional da Universidade Federal do Rio de Janeiro (MNRJ), os quais serão descritos no presente trabalho.

As dimensões são fornecidas em milímetros.

\section{Chryxinae Champion, 1898}

Chryxinae Champion, 1898: 180 (disc.); Costa Lima, 1940: 161

(cit.), 162 (chave); Wygodzinsky, 1949: 21 (cat.); Putshkov \& Putshkov, 1985: 8 (cat.); Maldonado Capriles, 1990: 21 (cat.); Schuh \& Slater, 1995: 153 (chave), 156 (diagnose.), Forero, 2004: 142 (diagnose).

Diagnose. Espécies de tamanho médio ou pequeno (3,1 a 9,0 mm de comprimento). Cabeça transversa, mais larga do que longa, fronte fortemente inclinada adiante dos olhos (Figs 1-5, 13-15). Sutura interocular distinta (Figs 2, 13 e 14). Ocelos presentes (Lentia corcovadensis), situados entre os ol hos (Fig. 2), ou ausentes (Figs 3, 13 e 14). Rostro forte e curto, fortemente encurvado (Figs 5 e 15). Pronoto com sutura transversal adiante da parte mediana (Figs 1-3, 13 e 14). Hemiélitros com o cório distintamente delimitado da membrana, que possui uma célula grande (Figs 1-3 e 13) (CHAMPION 1898, WYGODZINSKY 1946, SCHuH \& SLATER 1995).

\section{Chave para os gêneros de Chryxinae}

1. Presença de ocelos e processos aguçados na face ventral da cabeça. Cório com pequena célula costal (Fig. 2) .... Lentia

1'. Ausência de ocelos e processos na face ventral da cabeça (Figs 3 e 15). Cório sem pequena célula costal (Fig. 3) ... 2

2. Comprimento entre 8,0 a 9,0 mm. Cório sem nervuras visíveis; conexivo de coloração clara uniforme (Fig. 13) ......... W ygodzinskyella

2'. Comprimento de 3,6 ou 5,0 mm de comprimento. Cório com nervuras parcialmente visíveis. Conexivo com alternância de coloração escura e clara (Figs 1 e 3) ..... Chryxus

\section{Chryxus Champion, 1898}

Chryxus Champion, 1898: 181 (descr.); Lent \& Wygodzinsky, 1944: 167 (cit.); Wygodzinsky, 1946: 177-178 (cit.); Wygodzinsky, 1949: 21 (cat.); Usinger, 1952: 56 (diagnose diferencial); Putshkov \& Putshkov, 1985: 8 (cat.); Maldonado Capriles, 1990: 21 (cat.); Schuh \& Slater, 1995: 156 (cit.); Forero, 2004: 142 (cit., coment.).

Espécie-tipo: Chryxus tomentosus Champion, 1898 por designação subseqüente de WYGODZINSKY (1949).

\section{Chave para as espécies de Chryxus}

1. Macho com 5,0 mm de comprimento. Pernas de coloração ocreada uniforme. Cório amarelado, com quase toda a metade apical enegrecida; membrana esbranquiçada com mancha oval enegrecida no interior da célula discal e outra de formato lunular, enegrecida, que ocupa todo o ápice da membrana; nervuras da membrana claras (Fig. 1)

C. tomentosus

1'. Macho com 3,6 mm de comprimento. Pernas de coloração castanho amareladas, fêmures com tênues anéis escurecidos. Cório esbranquiçado com mancha transversal e pouco menos da metade apical externa enegrecidas; membrana castanho-escura, com mancha esbranquiçada na margem externa, junto ao ápice do cório e faixa clara na margem interna que inclui a margem interna da célula discal; nervuras da membrana mais enegrecidas (Figs 3 e 4) .......

Chryxus bahianus sp. nov.

\section{Chryxus bahianus sp. nov.}

Descrição. Holótipo. Macho. Comprimento total: 3,6. Pronoto: comprimento: 0,7, largura do lobo posterior: 1,1; largura máxima do abdome: 1,2.

Tegumento brilhante, com pêlos dourados muito longos e delicados, esparsos na cabeça e tórax e um pouco mais numerosos nos esternitos; hemiélitros foscos. 

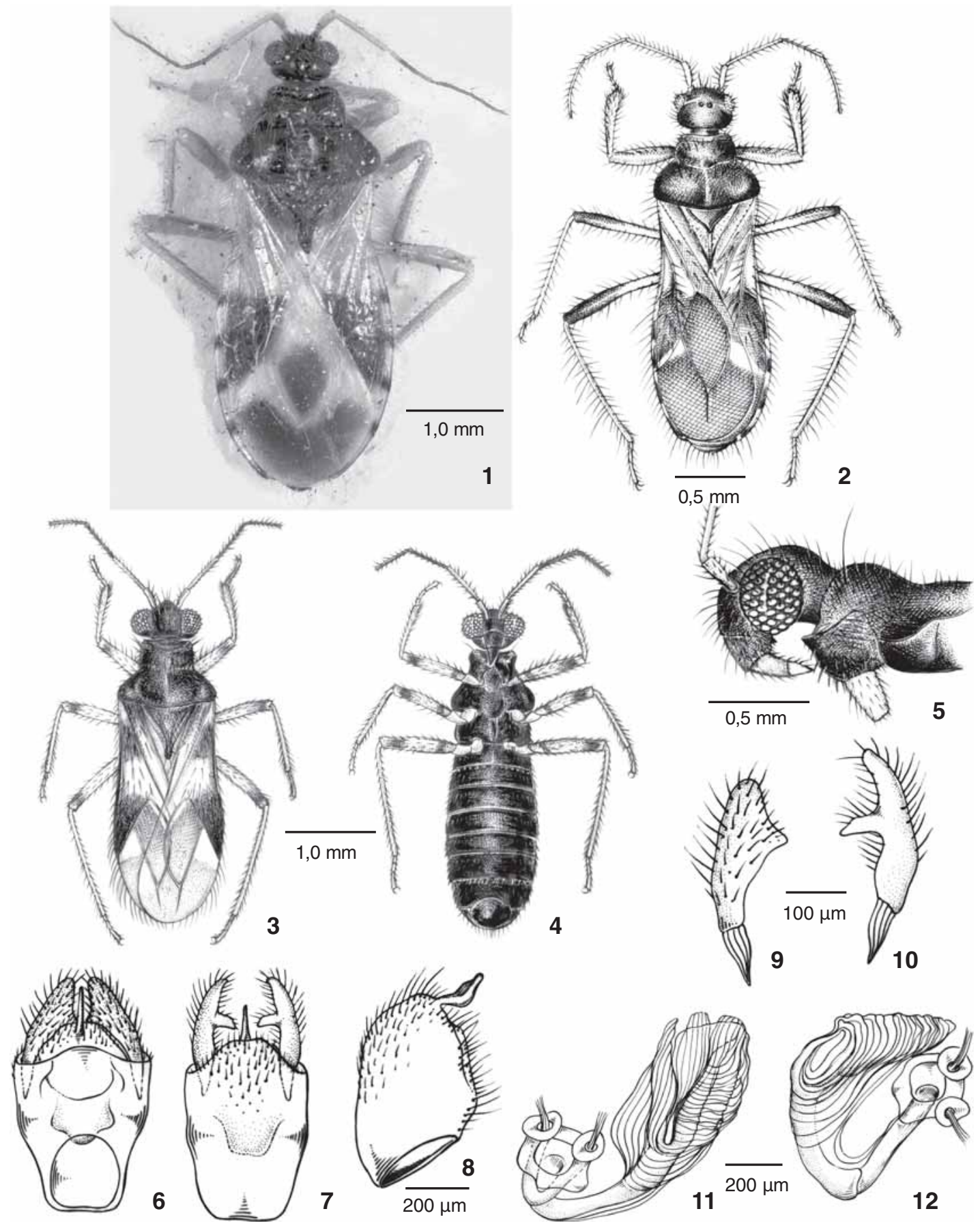

Figuras 1-12. (1) Chryxus tomentosus, síntipo macho depositado no British Museum, Londres. Cortesia de Michael Webb (BMNH), James Turner e Michael Wilson (NMGW); (2) Lentia corcovadensis, fêmea, vista dorsal; (3-12) Chryxus bahianus sp. nov., macho: (3) vista dorsal; (4) vista ventral; (5) cabeça e pronoto, vista lateral; (6) pigóforo e parâmeros vista dorsal; (7) pigóforo e parâmeros, vista ventral; (8) pigóforo, vista lateral; (9) parâmero, vista dorsal; (10) parâmero, vista ventral; (11) falo, vista dorsal; (12) falo, vista lateral.

Cabeça (Figs 3-5) enegrecida, fortemente inclinada ime diatamente adiante dos olhos; mais larga que o lobo anterior do pronoto; sulco transversal interocular representado por linha muito fina, no centro da qual parte outra dirigida para 
frente. Olhos globosos, salientes, pilosos, ocupando a maior parte da região cefálica em vista lateral. Rostro muito curto e forte, primeiro e segundo artículos sub-iguais em comprimento, o terceiro mais curto e fino; segmento I castanho-escuro, II castanho-claro e III amarelo-escurecido. Face ventral com processo ímpar mediano pouco desenvolvido. Tubérculos anteníferos inseridos na parte inclinada da cabeça, pouco distantes dos olhos, dirigidos para frente. Antena com pêlos Iongos e finos; primeiro artículo mais curto e engrossado; segundo cilíndrico; terceiro e quarto mais finos que os demais; primeiro esegundo antenômeros castanho-claros, terceiro e quarto escurecidos. Pescoço muito curto, castanho-avermelhado.

Tórax (Figs 3-5): pronoto com ângulos ântero-laterais distintos, pouco pronunciados; lobo anterior mais curto e estreito queo posterior; ângulos póstero-laterais arredondados; tegumento liso, brilhantee enegrecido; sulco interlobular bem marcado; sulco Iongitudinal raso ocupando o terço distal do lobo anterior e não alcançando a borda posterior do lobo posterior, aonde se apresenta mais estreito e fino. Escutelo triangular com rugosidade em sua parte central e espinho curto e simples, região central castanho-escura, o restante castanho-claro, com ápice do processo distal preto, pouco dilatado e dirigido para cima. Pleuras e esterno castanho-escurecidos; processo prosternal saliente e de ápice agudo; coxas anteriores castanhas; acetábulos medianos e posteriores, região acima do acetábulo mediano e coxas medianas e posteriores amarelados. Pernas de coloração castanho amarelado, fêmures com tênues anéis escurecidos em região sub-basal e subapical; fêmures um pouco espessados, principalmente os anteriores; tíbias cilíndricas, fóssulas esponjosas presentes na tíbia anterior, esta mais larga no ápice; tarsos trímeros, de coloração amarelada clara. Hemiélitros ultrapassando levemente o ápice do abdome; clavo castanho escuro; cório esbranquiçado, apresentando mancha transversal e região apical externa enegrecidas; membrana castanho-escura, com mancha esbranquiçada na margem externa, junto ao ápice do cório e faixa clara na margem interna queinclui a margem interna da célula discal; nervuras da membrana mais escuras. Conexivo castanho-avermelhado com cerca da metade distal de cada segmento escurecida.

Abdome. Esternitos castanho-avermelhados, escuros a enegrecidos nas partes Iaterais dos segmentos; esternito I ligeiramente carenado no meio, bordo anterior do segmento II com uma série de impressões sub-ovais (Fig. 4).

Genitália masculina (Figs 6-12): Pigóforo alongado de coloração escura; processo mediano afilado, curvo lateralmente. Parâmeros simétricos, com processo dentiforme na face interna em seu ponto médio. Falosoma membranoso.

Etimologia. O nome da espécie é alusivo ao estado da Bahia, Brasil, no qual o holótipo foi coletado.

Material examinado. Holótipo macho, Brasil. Bahia: Barro Preto (1443'S, 39²2'W), XII.2004, O. M. Marques leg., Coleção Entomológica do Museu Nacional da Universidade Federal do Rio de Janeiro (MNRJ).

Distribuição geográfica: Brasil (Estado da Bahia).

\section{Chryxus tomentosus Champion, 1898}

Chryxus tomentosus Champion, 1898: 181 (descr.), tab. XI, figs 9 e 9a; Lent \& Wygodzinsky, 1944: 167 (cit.) e 171 (cit.); Wygodzinsky, 1949: 21 (cat.); Usinger, 1952: 55, 56 (cit); Putshkov \& Putshkov, 1985: 8 (cat.); Maldonado Capriles, 1990: 21 (cat.); Forero, 2004: 142 (cit.).

Diagnose. Macho. (Fig. 1). Comprimento total: 5,0 mm. Coloração geral preta a enegrecida no lobo anterior e escutelo. Tegumento brilhante, recoberto de pêlos claros, muito longos e finos, incluindo os olhos e tórax. Antenas com os dois primeiros segmentos amarelados, os restantes escurecidos. Pernas de coloração ocreada uniforme. Cório amarelado com quase toda a metade apical enegrecida; mancha oval enegrecida no interior da célula discal e outra de formato lunular, enegrecida, que ocupa todo o ápice da membrana; nervuras da membrana claras. Conexivo amarelado com o ápice de cada segmento escurecido.

Distribuição geográfica: Guiana e Panamá.

\section{Lentia Wygodzinsky, 1946}

Lentia Wygodzinsky, 1946: 173-174 (descr.), 177-178 (diagnose diferencial), 179 (cit.); Wygodzinsky, 1949: 22 (cat.); Usinger, 1952: 55 (cit.); Putshkov \& Putshkov, 1985: 8 (cat.); Maldonado Capriles, 1990: 21 (cat.); Schuh \& Slater, 1995: 156 (cit.); Forero, 2004: 142 (cit.).

Espécie-tipo: Lentia corcovadensis Wygodzinsky, 1946, por designação original.

\section{Lentia corcovadensis Wygodzinsky, 1946}

Lentia corcovadensis Wygodzinsky, 1946: 174-177 (descr.), figs 1-12; Wygodzinsky, 1949: 22 (cat.); Usinger, 1952: 55 (cit.); Putshkov \& Putshkov, 1985: 8 (cat.); Maldonado Capriles, 1990: 21 (cat.); Schuh \& Slater, 1995: 156 (cit.); Forero, 2004: 142 (cit.).

Fêmea. (Fig. 2). Comprimento total: 3,1 mm. Superfície do corpo brilhante na cabeça e seus apêndices, no tórax, nas pernas e no abdome, com exceção de uma pequena célula costal do cório que é brilhante e semi-hialina, com pêlos dourados muito longos e delicados, em número moderado.

Cabeça castanho-avermelhada, não muito escura, de forma semi-oval, fortemente inclinada imediatamente adiante dos olhos, tão larga quanto o lobo anterior do pronoto, a face dorsal uniformemente convexa; sulco transversal interocular representado por linha fina, no centro da qual parte outra dirigida para frente. Olhos pequenos, pilosos, ocupando apenas uma pequena parte da face lateral da cabeça, com processos láteroventrais aguçados. Rostro curto e forte, primeiro artículo ligeiramente mais longo que o segundo, o terceiro muito mais curto; rostro enegrecido, com exceção do último artículo que é mais claro. Tubérculos anteníferos distintos. Antena com pêlos Iongos e finos; primeiro artículo mais curto e engrossado; segundo cilíndrico; terceiro e quarto mais finos e delicados; primeiro artículo castanho-avermelhado claro, segundo e terceiro 
castanho escuros, quarto branco com base e ápice com largos anéis pretos. Pescoço muito curto, enegrecido.

Tórax. Pronoto com ângulos ântero-laterais arredondados; lobo anterior mais curto e estreito que o posterior; ângulos póstero-laterais arredondados; tegumento liso, brilhante e enegrecido; sulco interlobular bem marcado; sulco longitudinal só visível no lobo posterior, profundo e que termina um pouco adiante da margem posterior. Escutelo triangular, com escavação anterior mediana, cujo disco é plano e limitado por bordos ele vados; espinho apical curto e forte, dirigido para cima e ligeiramente para trás. Pleuras e esterno castanho-claros; coxa anterior castanha; acetábulos medianos e posteriores, região acima do acetábulo mediano e coxas medianas e posteriores esbranquiçadas. Fêmures anteriores mais grossos que os medianos e posteriores; tíbia anterior mais curta que as demais, bastante alargada no ápice, na região da fóssula esponjosa que se encontra presente somente nas tíbias anteriores. Os 2/3 basais do fêmur anterior castanho escuros, terço apical, assim como as tíbias anteriores, castanho claras. Os 3/5 basais dos fêmures medianos e posteriores brancos, o restante escurecido, exceto por estreito anel apical amarelado. Tíbias medianas e posteriores castanhas, com base e ápice mais claros. Tarsos de coloração castanho clara a amarelada. Hemiélitros um pouco mais curtos que o ápice do abdome; clavo castanho escuro, base do cório esbranquiçada; membrana com uma mancha esbranquiçada na margem externa e uma outra na margem interna, ambas ao nível do ápice do cório; este com nervuras distintas e uma pequena célula costal. Conexivo com o terço anterior dos segmentos castanho avermel hado bastante claro, o restante de cor castanho escura. Abdome: esternitos castanho avermelhado, escuros; esternito II (primeiro visível) ligeiramente carenado no meio, o bordo anterior do segmento III com uma série de impressões sub-ovais.

Material examinado. Holótipo fêmea, Brasil. D.F. [Estado do Rio de Janeiro]: Rio de Janeiro, Botafogo, 24.II.1946, Wygodzinsky col., Coleção Entomológica do Museu Nacional da Universidade Federal do Rio de Janeiro (MNRJ).

Distribuição geográfica: Brasil (Estado do Rio de Janeiro).

\section{Wygodzinskyella Usinger, 1952}

W ygodzinskyella Usinger, 1952: 56 (diagnose diferencial); Putshkov \& Putshkov, 1985: 8 (cat.); Maldonado Capriles, 1990: 21 (cat.); Schuh \& Slater, 1995: 156 (cit.); Forero, 2004: 142 (cit.).

Espécie-tipo: Chryxus travassosi Lent \& Wygodzinsky, 1944, por designação original.

\section{Wygodzinskyella travassosi (Lent \& Wygodzinsky, 1944)}

Chryxus travassosi Lent \& Wygodzinsky, 1944: 167-171 (descr.), figs 1-19; Wygodzinsky, 1946: 177 (cit.); Wygodzinsky, 1949: 21 (cat.); Putshkov \& Putshkov, 1985: 8 (cat.)

W ygodzinskyella travassosi Usinger, 1952: 55 (cit.), 56 (desig. original como espécie tipo); Maldonado Capriles, 1990: 21 (cat.); Forero, 2004: 142 (cit.).
Descrição. Macho. Comprimento total: 8,0-8,5; pronoto: largura do lobo posterior: 2,6-2,7; Iargura máxima do abdome: 3,0-3,4.

Coloração geral pardo-alaranjada, com manchas escuras; corpo revestido por abundante pilosidade com pêlos finos, longos, dourados que só não existem na membrana dos hemiélitros.

Cabeça (Figs 13-15) enegrecida, com a parte anterior clara em dois espécimes, fortemente inclinada imediatamente adiante dos olhos; mais larga que o lobo anterior do pronoto; sulco transversal interocular nítido, no meio do qual nasce um sulco longitudinal que se bifurca anteriormente em " $Y$ ", cujas extremidades al cançam os tubérculos anteníferos. Ol hos globosos, salientes, pilosos, ocupando a maior parte da região cefálica em vista lateral. Rostro avermelhado, muito curto e forte, primeiro artículo maior que os demais e escurecido na base; segundo menor e mais delgado e o terceiro triangular. Tubérculos anteníferos inseridos na parte inclinada da cabeça, pouco distantes dos olhos, dirigidos para frente. Antena escurecida, com pêlos longos e finos; primeiro artículo mais curto e engrossado; segundo cilíndrico; terceiro e quarto mais finos.

Tórax (Figs 13-15): pronoto de forma trapezoidal; ânguIos ântero-laterais arredondados; sulco transversal interlobular bem pronunciado; lobo anterior com cerca de 1/3 do comprimento do posterior e mais estreito do que este último; ângulos póstero-laterais arredondados; tegumento liso, brilhante e enegrecido; sulco interlobular bem marcado; lobo posterior com sulco longitudinal mediano, no qual observam-se al gumas impressões escavadas transverso-ovais; regiões para-medianas do lobos anterior e posterior do pronoto castanho-escurecidas e as laterais e centrais mais claras. Em dois espécimes, o lobo anterior é claro com a coloração escurecida restrita ao terço distal do segmento. Escutelo triangular, com escavação central, a qual apresenta algumas rugosidades; ápice longo e agudo, elevado, cujo aspecto em ponta é melhor percebido em vista lateral. As regiões central e superior do escutel o são enegrecidas e o restante pardo-avermelhada. Pleuras e região esternal do tórax escurecidas, quase pretas com tonalidade avermel hadas junto às suturas. Coxas pardo-alaranjadas; fêmures e tíbias escurecidos com a região apical dos fêmures e basal das tíbias pardo-alaranjadas; tíbias anteriores com fosseta esponjosa saliente; tarsos escurecidos. Hemiélitros atingindo ou ultrapassando levemente o ápice do abdome. Cório de colorido pardoescuro, com o terço proximal mais claro em dois espécimes (Fig. 13); clavo mais escurecido sem nervuras evidentes; membrana enfumaçada, com somente duas nervuras que são bem nítidas por serem mais claras, quase esbranquiçadas, formando na região centro mediana da membrana uma única grande célula (Fig. 13). Conexivo com coloração alaranjada uniforme.

Abdome: esternitos castan ho-escurecidos com as margens laterais avermelhadas; presença de depressão ovalar rasa nas laterais do primeiro esternito; carena mediana presente neste e no segundo esternitos e pequena elevação mediana distal arredondada no sexto esternito.

Revista Brasileira de Zoologia 24 (1): 77-83, março 2007 

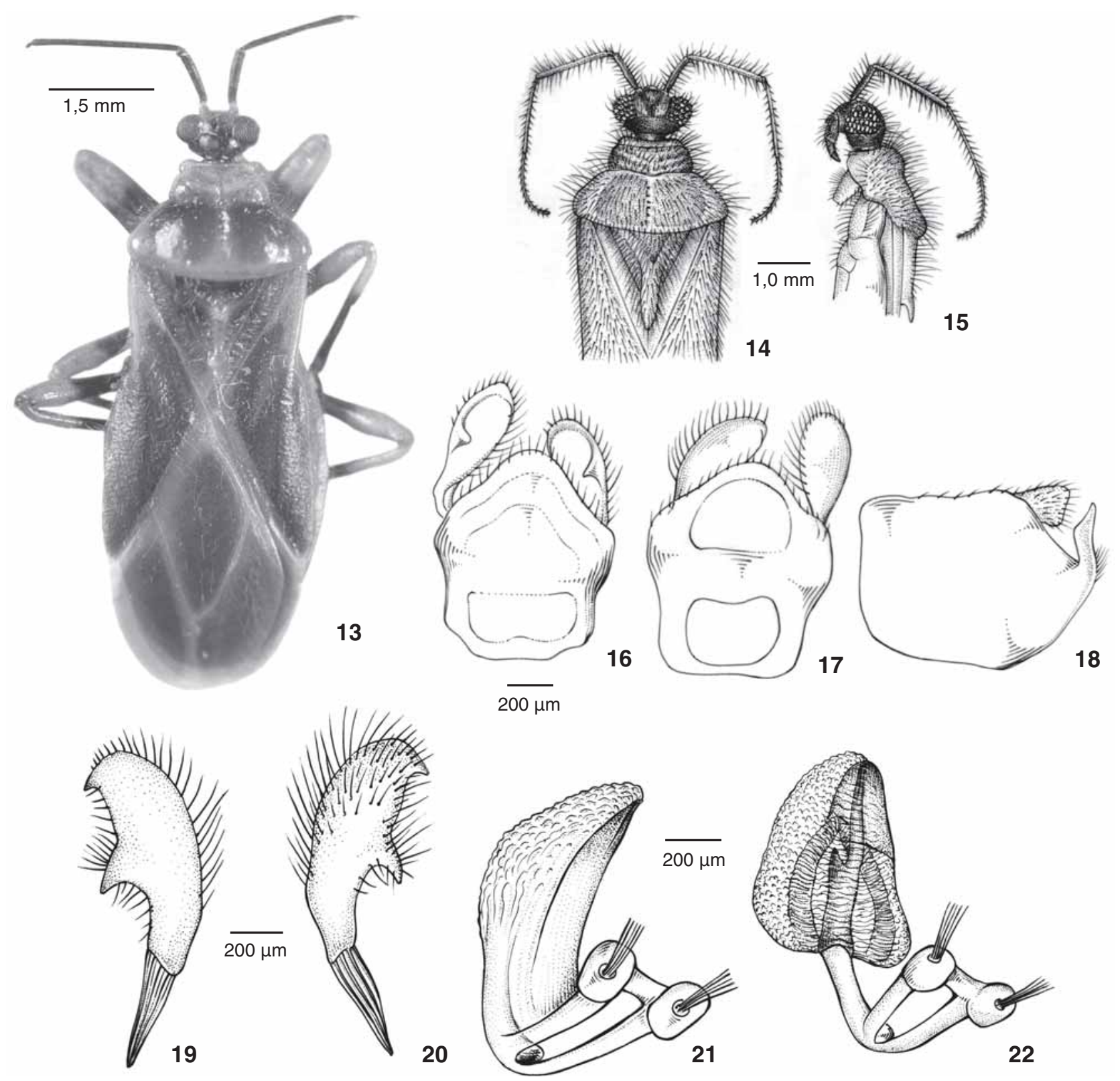

Figuras 13-21. (13-15) Wygodzinskyella travassosi, macho: (13) vista dorsal; (14) cabeça, tórax e base dos hemiélitros, vista dorsal; (15) cabeça e tórax, vista lateral; (16-22) W. travassosi: (16) pigóforo e parâmeros, vista ventral; (17)pigóforo e parâmeros, vista dorsal; (18) pigóforo, vista lateral; (19) parâmero, vista dorsal; (20) parâmero, vista ventral; (21) falo, vista ventral; (22) falo, vista dorsal.

Genitália masculina (Figs 15-22): Pigóforo de coloração escurecida, sub-poligonal; processo mediano afilado, somente visível em vista ventral, um pouco encurvado em vista lateral e de ponta afilada. Parâmeros simétricos, com processo dentiforme na face interna em seu ponto médio e ápice terminando em ponta parecida com o precedente e de direção paralela ao mesmo. Falosoma membranoso.
Material examinado. Chryxus travassosi Lent \& Wygodzinsky, 1944. Holótipo fêmea. Brasil. Mato Grosso, Bodoquena, XI.1941, Com. IOC [leg.]; macho, Brasil. Mato Grosso, Salobra, I.1941, Com. IOC [leg.], Com. IOC [leg.]; macho, Argentina. Vespúcio, Salta II, 1943 A.A., A.F. Prosen [leg.], Com. IOC [leg.], Coleção Entomológica do Instituto Oswaldo Cruz (IOC). W ygodzinskyella travassosi (Lent \& Wygodzinsky, 1944), 10/961, 
H. Lent [det.]. Macho. Brasil. Brasília, Goiás, 1000m, 30-15.V. 1957, Barros-Albuquerque [leg.], Coleção Entomológica do Museu Nacional da Universidade Federal do Rio de Janeiro (MNRJ).

Distribuição geográfica: Argentina (Misiones e Vespúcio) e Brasil (Estados de Goiás, Mato Grosso e São Paulo).

\section{DISCUSSÃO}

Chryxus bahianus $\mathbf{s p}$. nov. distingue-se de $\mathrm{C}$. tomentosus pel os caracteres constantes na chave para as espécies de Chryxus.

Chryxus bahianus $\mathbf{s p}$. nov. possui muitas semelhanças na coloração e aspecto geral com L. corcovadensis, incluindo o aspecto mais delicado dessas espécies em comparação com as demais espécies de Chryxinae, o colo muito curto e a cabeça muito larga, caracteres considerados por WYGODZINSKY (1946) na diagnose diferencial entre Lentia eChryxus. A comparação entreC. bahianus sp. nov. e L. corcovadensis, revelou muita semelhança entre as mesmas, incluindo as dimensões, coloração e a presença de impressões sub-ovais no segundo esternito do abdome.

Do mesmo modo, a descoberta de $C$. bahianus $\mathbf{s p}$. nov. reforça a tese de que $W$ ygodzinskyella é muito próximo de Chryxus. A presença de marcações escurecidas nas pernas da espécie descrita, antes tida como caráter diagnóstico de W ygodzinskyella, mostrou-se comum a ambos gêneros. O estudo da genitália dos machos de W. travassosi e C. bahianus $\mathbf{s p}$. nov. revel ou muitas coincidências, como a morfologia dos processos medianos dos pigóforos, dos parâmeros e do falo. Por outro lado, alguns caracteres apontados por UsINGER (1952), como a visibilidade das nervuras no cório e a forma do ápice do escutelo, podem não ser de valia para diferenciação genérica, seja pela possível variação inter ou intra-específica, seja pela subjetividade na determinação expressa pelo próprio USINGER (1952) ao caracterizar serem as nervuras "praticamente" indistinguíveis no cório opaco de W ygodzinskyella. Tais considerações corroboram o exposto por FORERo (2004), no sentido de que esses dois gêneros possam vir a ser objeto de sinonímia em futura revisão. No momento, o estudo da genitália masculina de duas espécies de Chryxinae, $W$. travassosi e $C$. bahianus \$p. nov., e a descoberta desta última sobreleva o fato de tratarse de um grupo de espécies muito próximas, cuja classificação genérica, contudo, ainda precisa encontrar melhores subsídios para sua fundamentação.

Constatou-se não existir dimorfismo sexual em W ygodzinskyella travassosi, a única espécie em que os dois sexos foram conhecidos e descritos até o momento.

\section{AGRADECIMENTOS}

Ao Almirante Centro de Estudos de Cacau pelo suporte financeiro; Dimitri Forero (Cornell University, USA), Manuel Baena (Inst. de Bachillerato, Ant. Gala, Córdoba, Espanha) e J.M. Bérenger (França); Michael Webb (BMNH), James Turner, Michael Wilson (National Museum and Gallery of Wales NMGW) e Gabriel Mejdalani (MNRJ).

\section{REFERÊNCIAS BIBLIOGRÁFICAS}

ChAMPION, G.C. 1899. Insecta Rhynchota. Hemiptera-Heteroptera, vol. 2, p. 229-243. In: F. D. Godman \& O. Salvin (Eds). Biologia Centrali Americana. Rhynchota. London, XIV+416p.

CostA LimA, A.M. 1940. Insetos do Brasil. Rio de Janeiro, Escola Nacional de Agronomia, Série didática, vol. 2, 351p.

Forero, D. 2004. Diagnosis de los géneros Neotropicales de la familia Reduviidae (Hemiptera: Heteroptera), y su distribución en Colombia (excepto Harpactorinae), p. 128-275. In: F. FERnÁndez; G. Andrade \& G. Amat (Eds). Insectosde Colombia. Bogotá, Universidad Nacional de Colombia, vol. 3, 604p.

Lent, H. \& P. Wygodzinsky. 1944. Sôbre uma nova espécie do gênero "Chryxus" Champion, 1898 (Chryxinae, Reduviidae, Hemiptera). Revista Brasileira de Biologia 4 (2): 167-171.

Maldonado Capriles, J. 1990. Systematic Catalogue of the Reduviidae of the World (Insecta: Heteroptera). Caribbean Journal of Sciences, Special edition, 694p.

PutSHKov, V. G. \& P. V. PuTSHKov. 1985. A Catalogueof theAssassinBugs Genera of the World (Heteroptera, Reduviidae). Kiev, Published by the authors, 137p.

SCHuh, R.T. \& J. A. Slater. 1995. True bugs of the world (Hemiptera: Heteroptera): classification and natural history. New York, Cornell University Press, 336p.

USINGER, R.L. 1943. A revised classification of the Reduvioidea with a new subfamily from South America (Hemiptera). Annals of the Entomological Society of America 36: 602-618.

USINGER, R.L. 1952. A new genus of Chryxinae from Brazil and Argentina (Hemiptera: Reduviidae). The Pan-Pacific Entomologist 28 (1): 55-56.

WYGodZINSKY, P. 1946. Sôbre um novo gênero e uma nova espé cie de Chryxinae e considerações sôbre a subfamília (Reduviidae, Hemiptera). Revista Brasileira de Biologia 6 (2): 173-180.

WYGodZINSKY, P. 1949. Elenco sistematico de los reduviiformes americanos. Instituto de Medicina Regional de la Universidad Nacional de Tucumán, Monografia 1: 1-102.

Recebido em 05.IV.2006; aceito em 23.II.2007. 